\title{
Erratum to: A Mobile Full-Time Daily System for Fetal Monitoring
}

Artem Bureev ${ }^{1}$, Elena Vaganova ${ }^{2}$, Dmitry Zhdanov $^{1,2}$, Ivan Zemlyakov ${ }^{1}$, and Ekaterina Dikman ${ }^{1}$

${ }^{1}$ Diagnostika + LLC, 634055, Tomsk, Russia

${ }^{2}$ National Research Tomsk State University, 634050, Tomsk, Russia

Original article:

MATEC Web of Conferences 79, 01026 (2016), DOI: 10.1051/matecconf/20167901026

In the section Acknowledgement, the line ", and the program of improving competitiveness of the TSU (project No. 8.2.31.2015)" must be deleted. 